\title{
Metabolic Changes After H2 15O-Positron Emission Tomography with Acetazolamide in a Patient with Moyamoya Disease: Case Report and Review of Previous Cases
}

\author{
Muroi, Carl ; Yonekawa, Yasuhiro ; Khan, Nadia ; Pangalu, Athina ; Keller, Emanuela
}

\begin{abstract}
Perioperative ischemic complications not directly related to surgery require special attention in patients with moyamoya disease; positron emission tomography (H(2) 15O-PET) and single-photon emission computed tomography have been considered indispensable for evaluating pre- and postsurgical cerebral hemodynamics. The clinical records of 14 patients with moyamoya disease who underwent 26 extracranial-intracranial bypass operations were reviewed with special reference to perisurgical complications. One patient developed multiple postoperative ischemic infarctions and died of ischemic brain edema. The history of this patient with prolonged acidosis is analyzed, and the role of metabolic changes induced by $\mathrm{H}(2)$ 15O-PET with acetazolamide challenge is reviewed. Seven (77.8\%) of nine patients operated on within 48 hours after H(2) 15O-PET with acetazolamide (group 1) developed metabolic acidosis, whereas only three (17.6\%) of 17 patients operated on $>48$ hours (group 2 ) after the examination had intraoperative $\mathrm{pH}$ of $<7.35$. In group 1 , the mean intraoperative $\mathrm{pH}$ was 7.328 , which was significantly lower than the mean $\mathrm{pH}$ of $7.393(\mathrm{P}<.0001)$ in group 2 . After $\mathrm{H}(2)$ 15O-PET with acetazolamide challenge, patients must be carefully observed concerning acidosis and volume state. We recommend at least 48 hours between examination and surgery for patients with moyamoya disease so that their conditions can stabilize. Furthermore, special care should be taken to avoid additional perioperative risk factors such as hypotension, hypocapnia, hypercapnia, and hypovolemia.
\end{abstract}

DOI: https://doi.org/10.1097/00008506-200304000-00011

Posted at the Zurich Open Repository and Archive, University of Zurich ZORA URL: https://doi.org/10.5167/uzh-192120

Journal Article

Accepted Version

Originally published at:

Muroi, Carl; Yonekawa, Yasuhiro; Khan, Nadia; Pangalu, Athina; Keller, Emanuela (2003). Metabolic Changes After H2 15O-Positron Emission Tomography with Acetazolamide in a Patient with Moyamoya Disease: Case Report and Review of Previous Cases. Journal of Neurosurgical Anesthesiology, 15(2):131-139.

DOI: https://doi.org/10.1097/00008506-200304000-00011 
Metabolic changes after $\mathrm{H}_{2}{ }^{15} \mathrm{O}-\mathrm{PET}$ examination using acetazolamide in a patient with Moyamoya disease: a case report with review of previous cases

Carl Muroi; Yasuhiro Yonekawa, MD; Nadia Khan, MD; "Athina Pangalu, MD; Emanuela Keller, MD

Department of Neurosurgery, University Hospital Zurich, Zurich, Switzerland "Institute of Neuroradiology, University Hospital Zurich, Zurich, Switzerland

\section{CORRESPONDENCE}

C. Muroi, c/o Dr. Emanuela Keller

Department of Neurosurgery

University Hospital of Zurich

Nordtrakt 1

Frauenklinikstrasse 10

$\underline{\mathrm{CH}-8091 \text { Zürich }}$

Switzerland

Tel.: 004112555671

Fax: 004114387

Email: ees@nch.unizh.ch 


\section{SUMMARY}

The occurrence of perioperative ischemic complications not directly related to surgery requires special attention in patients with Moyamoya disease. $\mathrm{H}_{2}{ }^{15} \mathrm{O}-\mathrm{PET}$ (positron emission tomography) and SPECT (single photon emission computed tomography) examinations have been considered to be indispensable for evaluating pre- and postsurgical cerebral hemodynamics. The clinical records of 14 patients with Moyamoya disease and 26 extracranial-intracranial (EC-IC) bypass operations were reviewed with special reference to perisurgical complications. One patient developed multiple postoperative ischemic infarctions and died of ischemic brain edema. The history of this patient with prolonged acidosis is analyzed and the role of metabolic changes induced by $\mathrm{H}_{2}{ }^{15} \mathrm{O}-\mathrm{PET}$ examination with acetazolamide challenge is focused. Seven of nine patients $(77.8 \%)$ operated within 48 hours after the $\mathrm{H}_{2}{ }^{15} \mathrm{O}$ PET examination with acetazolamide (group one) developed metabolic acidosis whereas only three of 17 patients (17.6\%) operated later than 48 hours (group two) after the examination showed intraoperative $\mathrm{pH}$ values below 7.35. In group one intraoperative $\mathrm{pH}_{\text {mean }}$ was 7.328 , which was significantly lower than $\mathrm{pH}_{\text {mean }} 7.393$ $(p<0.0001)$ of group two. Patients after $\mathrm{H}_{2}{ }^{15} \mathrm{O}-\mathrm{PET}$ examinations with acetazolamide challenge have to be carefully observed concerning acidosis and volume state. Time intervals of at least more than 48 hours between the examination and surgery are considered to be recommendable from our data to perform surgery in a stable condition of the patients with Moyamoya disease. Furthermore, special care should be taken to avoid additional perioperative risk factors such as hypotension, hypocapnia, hypercapnia and hypovolemia. 


\section{KEY WORDS}

Moyamoya disease; acetazolamide; cerebral blood flow; perioperative treatment; $\mathrm{H}_{2} \mathrm{O}-\mathrm{PET}$

\section{INTRODUCTION}

Moyamoya disease is a unique cerebrovascular disease with a much higher incidence in Japanese and other Asians than in Caucasians $(1,2)$. It is characterized by a bilateral progressive cerebrovascular occlusion of the terminal portion of the internal carotid artery with a spontaneously developed collateral network, the socalled Moyamoya vessels (1). The occurrence of these typical findings in association with other diseases is called Moyamoya syndrome (1). Moyamoya disease is subdivided into a juvenile and an adult type. The typical clinical manifestations are cerebral ischemia and intracerebral hemorrhage (1). Transient ischemic attacks (TIAs) and permanent ischemia are the most frequent manifestations in Europe (3). Since the late seventies cerebrovascular reconstruction surgery is successfully performed to treat ischemic symptoms in Moyamoya disease. Nevertheless the occurrence of perioperative ischemic complications not directly related to surgical technique is a serious problem and requires special attention $(4,5,6,7,8,9)$. So far literature dealing with aspects of perioperative treatment in patients with Moyamoya disease is sparse. We report on a patient with Moyamoya disease who showed metabolic acidosis after $\mathrm{H}_{2}{ }^{15} \mathrm{O}-\mathrm{PET}$ (positron emission tomography) examination using acetazolamide and severe postoperative ischemic complications. Based on the case, the role of metabolic changes after $\mathrm{H}_{2}{ }^{15} \mathrm{O}-\mathrm{PET}$ examinations using 
acetazolamide is discussed, reviewing our experience in perioperative treatment of 14 patients with Moyamoya disease or syndrome with 26 operations with extracranial-intracranial (EC-IC) bypass surgery.

\section{CASE REPORT}

The 36 years old female patient, presented with right sided hemiparesis, recovered completely within seven days. The preoperative MRI showed subacute infarctions in the left frontal and fronto-parietal region (fig. 1). Angiography presented the typical Moyamoya disease pattern (fig. 2 and 3). There was no history of seizures. After an interval of three weeks without any symptoms, the patient underwent 2 bypasses (frontal branch of STA- prerolandic branch of MCA, parietal branch of STA- angular artery, branch of MCA). $\mathrm{H}_{2}{ }^{15} \mathrm{O}-\mathrm{PET}$ examination with acetazolamide challenge was performed 13 hours before the operation (fig. 4). Anesthesia was induced with propofol $90 \mathrm{mg}$ i.v., followed by continuous infusion of propofol 300mg/h and fentanyl $300 \mathrm{ug} / \mathrm{h}$ for the first three hours followed by remifentanyl $700 \mathrm{ug} / \mathrm{h}$. No volatile anesthetics were used. During the operation and postoperatively there were no signs of hypotension (mean arterial pressure (MAP) between 80 and $110 \mathrm{mmHg}$ ) or hypovolemia (central venous pressure (CVP) between 5 to $8 \mathrm{mmHg}$, normal serum lactate). Body temperature, obtained from the ear, decreased from $36.8^{\circ} \mathrm{C}$ to $35.6^{\circ} \mathrm{C}$ during the operation and increased to a maximal value of $38.0{ }^{\circ} \mathrm{C}$ postoperatively. Hematocrit preoperatively was $34 \%$ and decreased to a minimal value of $30 \%$ postoperatively. First blood gas analysis during the operation showed an arterial pH of $7.30, \mathrm{HCO}_{3}^{--}$of $14.7 \mathrm{mmol} / \mathrm{l}$ and $\mathrm{BE}$ of --9.1 . The patient was initially 
hyperventilated with a $\mathrm{PaCO}_{2}$ of $3.7 \mathrm{kPa}$. Artificial ventilation after 15 minutes was adapted and $\mathrm{PaCO}_{2}$ at the end of the operation was $4.7 \mathrm{kPa} .50 \mathrm{ml}$ of $\mathrm{Na}$-bicarbonate $8.4 \%$ were given during the operation and at the end of the operation $\mathrm{pH}$ was 7.39 , $\mathrm{HCO}_{3}-21.0 \mathrm{mmol} / \mathrm{l}$ and $\mathrm{BE}-2.6$. Immediately after the operation the patient woke up without any neurological deficit. First blood gas analysis in the neurosurgical intensive care unit showed an arterial $\mathrm{pH}$ of $7.47, \mathrm{HCO}^{---}$of $20.1 \mathrm{mmol} / \mathrm{l}$, $\mathrm{BE}$ of --4.2 and $\mathrm{PaCO}_{2}$ of $4.7 \mathrm{kPa}$ during spontaneous ventilation and Serum- $\mathrm{Na}^{+}$of $143 \mathrm{mmol} / \mathrm{l}$. During the early postoperative period MAP ranged between 90 and $110 \mathrm{mmHg}$, hematocrit was $30 \%$, body temperature was $36.8{ }^{\circ} \mathrm{C}$, and urinary output ranged between 60 to $120 \mathrm{ml} /$ hour. Six hours after the operation the patient deteriorated with generalized seizures. Arterial blood gas analysis taken 5 minutes before the event showed that $\mathrm{pH}$ decreased to $7.35, \mathrm{HCO}_{3}^{--}$to $18.2 \mathrm{mmol} / \mathrm{l}, \mathrm{BE}$ to -5.2 and a $\mathrm{PaCO}_{2}$ to $4.1 \mathrm{kPa}$. Serum-Na+ was stable with $141 \mathrm{mmol} / \mathrm{l}$. Immediate emergency resuscitation with induction of anesthesia (etomidate $0.3 \mathrm{mg} / \mathrm{kg}$ intravenously, combined with rocuroniumbromid $0.8 \mathrm{mg} / \mathrm{kg}$ and thiopental $5 \mathrm{mg} / \mathrm{kg}$ ), endotracheal intubation and cardiovascular stabilization was performed. Arterial blood gas values normalized after $50 \mathrm{ml} \mathrm{Na-bicarbonate} 8.4 \%$ intravenously. An emergency CT scan was carried out and showed multiple ischemias in the right MCA territory. Duplex sonography showed leftsided EC-IC bypass to be patent. No signs of cerebral vasospasm (mean blood flow velocities from middle, anterior and posterior cerebral arteries below $100 \mathrm{~cm} / \mathrm{sec}$ ) were documented. Assuming a critical diminished perfusion over the right hemisphere emergency EC-IC bypass (parietal branch of STA - angular artery, branch of MCA + frontal branch of STA - middle internal frontal branch of ACA) on the right side was performed without complications. At the end of the operation a subdural probe for intracranial pressure (ICP) monitoring was 
inserted. Because of increasing ICP values over $20 \mathrm{mmHg}$ the patient remained intubated, sedated (fentanyl infusion $5 \mathrm{ug} / \mathrm{kg} / \mathrm{h}$ and midazolam $0.4 \mathrm{mg} / \mathrm{kg} / \mathrm{h}$ ) and was treated with thiopental coma combined with hypothermia. After an additional loading dose of $5 \mathrm{mg} / \mathrm{kg}$ the dosage of thiopental was adapted to a burst suppression pattern in continuous EEG-monitoring. Postoperative CT scan showed multiple infarctions on both hemispheres (fig. 5). A decompressive craniectomy was performed. The patient died with ischemic brain edema induced by untreatable ICP elevations and the clinical signs of brain herniation.

\section{DISCUSSION}

A 36 years old female patient with fatal perioperative ischemic complication on the not operated side is reported. This female patient, with multiple postoperative ischemic infarctions, showed a metabolic acidosis, twice treated with $50 \mathrm{ml} \mathrm{Na-}$ bicarbonate $8.4 \%$, which persisted over 30 hours postoperatively. There was only a two hours period of mild hyperventilation during the operation, no episode of hypotension, no signs of hypovolemia or hemoconcentration occurred and no volatile anesthetics were used. Although the precise mechanisms leading to multiple cerebral infarctions remain speculative, occurring metabolic acidosis may be an event we have to pay attention in the perioperative treatment of patients with Moyamoya disease.

Metabolic changes after $\mathrm{H}_{2}{ }^{15} \mathrm{O}-\mathrm{PET}$ with acetazolamide: Ischemic events induced by acetazolamide challenge are described in single patients $(10,11)$. Lee et al. report a case with acetazolamide-induced Gerstmann syndrome (10). An other patient with 
a stenosis of the midportion of the basilar artery, developing reversible pontine ischemia immediately after acetazolamide challenge has been described (11). In a series of 9 patients with occlusion of the internal carotid artery, Vorstrup and coauthors found 2 patients after acetazolamide test showing a paradoxical decrease in focal CBF, which has been designated the steal phenomenon (12). Acetazolamide, a carbonic anhydrase inhibitor, is known as a diuretic agent and causal agent in metabolic acidosis (13). Acetazolamide is widely used for the treatment of glaucoma. Severe metabolic acidosis, rarely reported, occurs predominantly among elderly people, in patients with renal failure, diabetic type IV renal tubular acidosis and during concomitant use of other nephrotoxic drugs $(14-18)$. Brechue et al. reported after application of clinical doses of acetazolamide a reduction in body fluid compartments leading to a moderate isotonic hypovolemia (13). Hematocrit increased significantly and significant loss of plasma water was documented. Furthermore the authors found metabolic acidosis with a significant decrease in venous $\mathrm{pH}$ and plasma $\mathrm{HCO}_{3}^{--}$. Acetazolamide changes the functional status of the carbonic anhydrase of the central nervous system $(19,20)$. Javaheri et al. described that intravenous administration of $50 \mathrm{mg} / \mathrm{kg}$ to $100 \mathrm{mg} / \mathrm{kg}$ acetazolamide results in a considerable drop of the carbonic anhydrase concentration in the CSF (cerebrospinal fluid) in isocapnic metabolic acidosis (20). Carbonic anhydrase seems to be the major factor in maintaining $\mathrm{CSF} \mathrm{HCO}_{3}^{--}$level in isocapnic metabolic acidosis when $\mathrm{HCO}_{3}^{--}$diffuses from CSF to blood $(19,20)$. Neither $\mathrm{HCO}_{3}^{--}$nor the arterial $\mathrm{PCO}_{2}$ may influence the vascular tone per se, but the changes in perivascular $\mathrm{pH}$ due to changes in $\mathrm{CSF} \mathrm{HCO}_{3}^{--}$concentration or arterial $\mathrm{PCO}_{2}$ may induce cerebrovascular constriction or dilatation (21). In vitro low pH in CSF relaxes cerebral vascular muscle and high $\mathrm{pH}$ contracts the muscle. Application of solutions with varying $\mathrm{PCO}_{2}$ or 
varying $\mathrm{HCO}_{3}^{--}$concentration had no effect until the $\mathrm{pH}$ was allowed to change (22). Britton et al. demonstrated an inverse linear relationship between the CSF $\mathrm{pH}$ and total CBF (cerebral blood flow) (23). CSF acidity was changed by altered $\mathrm{HCO}_{3}^{--}$ concentration while arterial $\mathrm{PCO}_{2}$ was kept constant. It could be demonstrated that both total and regional CBF values depend directly on CSF acidity. Regli et al. investigated the effects of acetazolamide on cerebral infarction after unilateral experimental occlusion of the middle cerebral artery in adult cats (24). Neurological deficits were more severe and the ischemic infarctions were more extended in animals given acetazolamide compared to control animals. The authors conclude that the acetazolamide induced decrease of $\mathrm{pH}$ in nonischemic brain tissue may be harmful for ischemic areas because vasodilatation in nonischemic brain may steal blood away from the area supplied by the compromised vessel.

Other perioperative risk factors: Sumikawa et al. reported postoperative complications after anaesthetizing four patients with Moyamoya disease for surgical revascularization (5). They suggested that hypocapnia might be the main cause of neurological deficits after surgical treatment. The authors suppose that hypocapnia might steal blood from the area supplied by the compromised vessels. Iwama et al. retrospectively analyzed 21 patients with childhood Moyamoya disease who experienced ischemic complications not directly related to the surgery but during the perioperative period (4). The authors found that frequent occurrence of TIAs as an indicator of the instability of cerebral hemodynamics is a significant risk factor for perioperative ischemic complications. Multifactorial analysis showed that hypotension and hypocapnia did not independently affect the occurrence of complications, probably because they were rapidly treated and their duration was controlled. On the other hand, the incidence of hypercapnia was significantly higher in patients with 
perioperative ischemic events. Another perioperative risk factor may be the use of volatile anesthetics such as isoflurane because of their strong cerebral vasodilatative effects $(25,26)$. Global hyperemia due to cerebrovascular dilatation may cause intracerebral steal in compromised areas (26).

Systematic evaluation of charts and perioperative blood gas analysis of Moyamoya patients: The charts and imaging studies of 14 patients with Moyamoya disease or syndrome who underwent 26 EC-IC bypass surgery sessions between November 1997 and February 2001 at the Department of Neurosurgery, University Hospital Zurich, were reviewed. Patient characteristics are given in table 1. The clinical records were studied with special reference to intra- and postoperative mean arterial blood pressure, to blood gas data, the occurrence of postoperative ischemic complications and to the time between $\mathrm{H}_{2}{ }^{15} \mathrm{O}-\mathrm{PET}$ examination and the operation. All patients underwent $\mathrm{H}_{2}{ }^{15} \mathrm{O}-\mathrm{PET}$ examination using acetazolamide before surgery. For the standard $\mathrm{H}_{2}{ }^{15} \mathrm{O}-\mathrm{PET}$ scanning, $1 \mathrm{~g}$ of acetazolamide was injected intravenously in adult patients and 0,1 to $0,5 \mathrm{~g}$ in pediatric patients as a bolus over $2 \mathrm{~min}$. Before and during the operation hypovolemia was carefully avoided. Total intravenous anesthesia using propofol and fentanyl or remifentanyl was performed. In all patients an arterial catheter was placed to measure arterial pressure continuously and a central venous line to control central venous pressure (CVP). To avoid hyper- or hypoventilation the end-tidal $\mathrm{CO}_{2}$ concentration was measured continuously. Blood gas analysis (Ciba Corning system) were performed immediately at the beginning of the operation, after the induction of anesthesia and as soon as possible after postoperative arrival of the patient in the neurosurgical intensive care unit. Concerniong the surgical technique, classical STA (superficial temporal artery) MCA (middle cerebral artery) bypass was performed unilateral or bilateral routinely. 
After bypass surgery the patients were supervised and treated in the neurosurgical intensive care unit for 24 hours. Non surgical technique related postoperative complications were described as the patient developing transient or permanent neurological deficits or generalized seizures. If deficits or seizures occurred intracerebral hemorrhage was excluded with CT scan examination and EC-IC bypass was documented to be patent with extra-/transcranial Doppler sonography. In 14 patients with Moyamoya disease with $26 \mathrm{EC}$-IC bypass operations one fatal ischemic complication on the not operated side occurred (table 1). Perioperative data were available from 26 EC-IC bypass sessions in 14 Moyamoya patients. Patient characteristics were expressed as mean $( \pm S D)$. The Mann Whitney U-test was used to compare $\mathrm{pH}, \mathrm{HCO}_{3^{--}}$and $\mathrm{PaCO}_{2}$ between different cases. Statistical significance was assumed at a $\mathrm{p}$-value $<0.05$. Mean time from $\mathrm{H}_{2}{ }^{15} \mathrm{O}-\mathrm{PET}$ examination to the operation in all patients was 665 hours. The values of blood gas analysis were compared between two groups (table 2). Group one included nine cases in which EC-IC bypass surgery was performed within 48 hours after the $\mathrm{H}^{2}{ }_{15} \mathrm{O}-\mathrm{PET}$ examination with acetazolamide. Group two comprised the 17 cases where the operation was performed more than 48 hours after the $\mathrm{H}_{2}{ }^{15} \mathrm{O}-\mathrm{PET}$ examination with acetazolamide. In group one seven from nine patients (77.8\%) showed intraoperative $\mathrm{pH}$ values below 7.35 corresponding with metabolic acidosis, whereas only three from 17 patients (17.6\%) in group two had $\mathrm{pH}$ values below 7.35 . In group one intraoperative $\mathrm{pH}_{\text {mean }}$ was 7.328 , which was significantly lower than in group two with $\mathrm{pH}_{\text {mean }} 7.393(\mathrm{p}<0.0001)$. Intraoperative $\mathrm{HCO}_{3}^{--}$was significantly lower in group one compared to group two (17.6 compared to $20.1 \mathrm{mmol} / \mathrm{l} ; \mathrm{p}=0.0165$ ). Base excess (BE) was lower in group one than in group two $(--7.0$ compared to $--3.5 ; p=0.0165)$. The patients were normoventilated during the operation without differences between the 
two groups. After the operation $\mathrm{pH}_{\text {mean }}$ in all patients increased from 7.370 to 7.383 . $\mathrm{pH}_{\text {mean }}$ still tended to be lower in group one than in group two but without significance. $\mathrm{HCO}_{3}^{--}$mean postoperatively was still significantly lower in group one compared to group two (18.1 compared to $20.5 \mathrm{umol} / \mathrm{l} ; \mathrm{p}=0.0132$ ). Time interval between the $\mathrm{H}_{2}{ }^{15} \mathrm{O}$-PET examination with acetazolamide and the operation correlated with the $\mathrm{pH}$ values (Spearman $\mathrm{r}=0.52 ; \mathrm{p}<0.001$ ) and with the $\mathrm{HCO}_{3}^{--}$ values (Spearman $r=0.77 ; p<0.001$ ). In patients operated within 48 hours after the $\mathrm{H}_{2}{ }^{15} \mathrm{O}-\mathrm{PET}$ with acetazolamide metabolic acidosis occurred significantly more often and more pronounced than in patients operated later than 48 hours after the examination. Six patients underwent bilateral surgical revascularization in two sessions with two different time intervals after the $\mathrm{H}_{2}{ }^{15} \mathrm{O}-\mathrm{PET}$ examination with acetazolamide challenge (within 48 hours and after 48 hours). Box plots with the values obtained from the same patients in the two sessions are given in figure 6 . $\mathrm{pH}_{\text {mean }}$ and $\mathrm{HCO}_{3}{ }^{-}$mean obtained during surgery within 48 hours after the $\mathrm{H}_{2}{ }^{15} \mathrm{O}$-PET were significantly lower than the corresponding values obtained during surgery later than 48 hours after the examination (7.313 compared to 7.388 : $p=0.0152 ; 17.3$ compared to $20.3 \mathrm{mmol} / \mathrm{l} ; \mathrm{p}=0.0299)$. $\mathrm{PaCO}_{2 m e a n}$ was not different in the two sessions (4.6 kPa in both sessions).

Implications for perioperative treatment of patients with Moyamoya disease. $\mathrm{H}_{2}{ }^{15} \mathrm{O}$ PET with acetazolamide loading test may lead to hypovolemia, systemic metabolic acidosis and acidosis in the CSF. CSF acidosis may cause a reactive dilatation of unimpaired vessels (23). This may result in a decrease of perfusion in chronic ischemic areas in which the vessels are already maximally dilated (26). Acetazolamide induced effects in CSF may last on even if the drug has essentially disappeared from the general circulation (27). Maren injected $5 \mathrm{mg} / \mathrm{kg}$ acetazolamide 
i.v. in dogs and found significant concentrations in the choroid plexus as a tissue enzyme site still after 6 days (27). These acetazolamide induced disturbances might become clinically relevant if EC-IC bypass surgery is performed early after the $\mathrm{H}_{2}{ }^{15} \mathrm{O}$ PET examination with acetazolamide. Additional perioperative factors such as hypocapnia, hypercapnia, hypotension, hypovolemia or volatile anesthetics may aggravate cerebral hemodynamic imbalance. To prevent perioperative ischemic complication efforts must be made to establish optimal perioperative conditions. However, $\mathrm{H}_{2}{ }^{15} \mathrm{O}-\mathrm{PET}$ or SPECT examinations using acetazolamide can demonstrate cerebral hemodynamic changes after surgery and have been considered to be indispensable for evaluating pre- and postsurgical cerebral hemodynamics $(28,29)$. Patients after $\mathrm{H}_{2}{ }^{15} \mathrm{O}-\mathrm{PET}$ or SPECT examinations therefore have to be carefully observed concerning acidosis and volume state. On the basis of our cases, we recommend that a time interval of more than 48 hours should be kept between the $\mathrm{H}_{2}{ }^{15} \mathrm{O}-\mathrm{PET}$ or SPECT examination with acetazolamide challenge and surgery. The present illustrative case might not give evidence enough, that acidosis has the potential to induce cerebral ischemia. Nevertheless, occurring metabolic acidosis may be an event we have to pay attention in the perioperative treatment of patients with Moyamoya disease after the $\mathrm{H}_{2}{ }^{15} \mathrm{O}-\mathrm{PET}$ examination with acetazolamide. Furthermore, special care should be taken to avoid additional risk factors such as hypotension, hypocapnia, hypercapnia and hypovolemia. 


\section{REFERENCES}

1. Yonekawa Y, Taub E. Moyamoya disease: Status 1998. The Neurologist 1999;5:13-23.

2. Goto Y, Yonekawa Y. Worldwide distribution of moyamoya disease. Neurol Med Chir (Tokyo) 1992;32:883-86.

3. Yonekawa $\mathrm{Y}$, Ogata N, Kaku $\mathrm{Y}$, et al. Moyamoya disease in Europe, past and present status. Clin Neurol Neurosurg 1997;99 Suppl 2:58-60.

4. Iwama T, Hashimoto N, Yonekawa Y. The relevance of hemodynamic factors to perioperative ischemic complications in childhood moyamoya disease. Neurosurgery 1996;38:1120-26.

5. Sumikawa K, Nagai H. Moyamoya disease and anesthesia. Anesthesiology 1983;58:204-5.

6. Sakamoto T, Kawaguchi M, Kurehara $\mathrm{K}$, et al. Postoperative neurological deterioration following the revascularization surgery in children with moyamoya disease. J Neurosurg Anesthesiol 1998;10:37-41.

7. Sakamoto T, Kawaguchi M, Kurehara $\mathrm{K}$, et al. Risk factors for neurologic deterioration after revascularization surgery in patients with moyamoya disease. Anesth Analg 1997;85:1060-5.

8. Nomura S, Kashiwagi S, Uetsuka S, et al. Perioperative management protocols for children with moyamoya disease. Childs Nerv Syst 2001;17:270-4.

9. Kansha M, Irita K, Takahashi S, et al. Anesthetic management of children with moyamoya disease. Clin Neurol Neurosurg 1997;99 Suppl 2:110-3.

10. Komiyama M, Nishikawa M, Yasui T, et al. Reversible pontine ischemia caused by acetazolamide challenge. AJNR 1997;18(9):1782-4. 
11. Lee YT, Wu JC, Chan FK. Acetazolamide-induced Gerstmann syndrome. Int J Clin Pract 1999;53(7):560-1.

12. Vorstrup S, Brun B, Lassen NA. Evaluation of the cerebral vasodilatatory capacity by the acetazolamide test before EC-IC bypass surgery in patients with occlusion of the internal carotid artery. Stroke 1986;17(6):1291-8

13. Brechue WF, Stager JM, Lukaski HC. Body water and electrolyte responses to acetazolamide in humans. J Appl Physiol 1990;69:1397-401.

14. Epstein DL, Grant WM. Carbonic anhydrase onhibitor side effects. Arch Ophtalmol 1977;95:1378-82.

15. Heller I, Halevy J, Cohen S, et al. Significant metabolic acidosis induced by acetazolamide. Not a rare complication. Arch Intern Med 1985;145:1815-7.

16. Rousseau P, Fuentevilla CA. Acetazolamide and salicylate interaction in the elderly: a case report. J Am Geriatr Soc 1993;41:868-9.

17. Maisey DN, Brown RD. Acetazolamide and symptomatic metabolic acidosis in mild renal failure. Br Med J (Clin Res Ed) 1981;283:1527-8.

18. Elinav E, Ackerman Z, Gottehrer NP, et al. Recurrent life-threatening acidosis induced by acetazolamide in a patient with diabetic type IV renal tubular acidosis. Ann Emerg Med 2002;40(2):259-60.

19. Herrera L, Kazemi H. CSF bicarbonate regulation in metabolic acidosis: Role of $\mathrm{HCO}_{3}{ }^{--}$formation in CNS. J Appl Physiol 1980;49(5):778-83.

20. Javaheri S, Kennely J, Runck CD, et al. Cerebrospinal fluid ions in metabolic acidosis in dogs: Effects of acetazolamide. J Appl Physiol 1986;61(2):633-9.

21. Kontos HA, Raper AJ, Patterson JL. Analysis of vasoactivity of local $\mathrm{pH}, \mathrm{CO}_{2}$ and on pial vessels. Stroke 1977;8(3):358-60. 
22. Wahl M, Deetjen P, Thurau K, et al. Micropuncture evaluation of the importance of perivascular $\mathrm{pH}$ for the arteriolar diameter on the brain surface. Pfluegers Arch 1970;316:152-63.

23. Britton SL, Lorenz OL, Davies DG. Effect of cerebral extracellular fluid acidity on total and regional cerebral blood flow. J Appl Physiol 1979;47(4):818-26.

24. Regli F, Yamaguchi T, Waltz AG. Effects of acetazolamide on cerebral ischemia and infarction after experimental occlusion of middle cerebral artery. Stroke $1971 ; 2: 456-60$.

25. Sato K, Shirane R, Masato K, et al. Effect of inhalational anesthesia on cerebral circulation in moyamoya disease. J Neurosurg Anesthesiol 1999;11(1):25-30.

26. Oshima H, Katayama $\mathrm{Y}$, Hirayama T. Intracranial steal phenomenon associated with global hyperemia in moyamoya disease during revasculararisation surgery. $J$ Neurosurg 2000;92:949-54.

27. Maren T.H. Carbonic anhydrase: Chemistry, physiology, and inhibtion. Physiol Rev 1967;47(4):597-765.

28. Kuwabara $\mathrm{Y}$, Ichiya $\mathrm{Y}$, Sasaki M, et al. Cerebral hemodynamics and metabolism in moyamoya disease - a positron emission tomography study. Clin Neurol Neurosurg 1997;99 Suppl 2:74-8.

29. Ikezaki K, Matsushima T, Kuwabara $\mathrm{Y}$, et al. Cerebral circulation and oxygen metabolism in childhood moyamoya disease: A positron emission tomography study. J Neurosurg 1994;81:843-50. 


\section{FIGURE LEGENDS}

Fig. 1. Preoperative MRI, axial T2-weighted image: Subacute infarction in the left frontal and temporo-parietal region.

Fig. 2. Preoperative left internal carotid angiogramm: Arterial phase shows the typical Moyamoya pattern. Stenosis of the A1- and M1-segment with collateral lenticulostriatae arteries. A: AP view. B: Oblique view.

Fig. 3. Preoperative right internal carotid angiogramm: Late arterial phase shows slightly stenosis of the C1-segment. A: AP view. B: Lateral view.

Fig. 4. Preoperative PET examination with acetazolamide test. Top row: CBF at baseline. Reduced perfusion can be seen in the left parietal region. Middle row: CBF after acetazolamide loading. Bottom row: CBF reserve capacity. Reserve capacity is reduced except cerebellar, occipital, in the thalamus and striatum. Note the steal phenomenon in the right frontal region.

Fig. 5. CT examination shows severe acute infarctions in the right MCA and $A C A$ territory on both sides. Brain edema resulting in brain herniation.

Fig.6. Patients who had surgeries with two different intervals. In six patients bilateral surgical revascularization was performed in two sessions with two different time intervals. Right box plots show median values, $25 \%$ and $75 \%$ percentiles and maximal values obtained during surgery with a time interval of more than 48 hours 
after the $\mathrm{H}_{2}{ }^{15} \mathrm{O}-\mathrm{PET}$ examination with acetazolamide. Left columns show the values obtained during surgery with a time interval of less than 48 hours after the $\mathrm{H}_{2}{ }^{15} \mathrm{O}-\mathrm{PET}$ examination with acetazolamide.

Table 1. Patient characteristics in all patients and patient subgroups

$\begin{array}{lll} & \text { All patients } & \text { Group } 1 \\ \text { Group } 2 & \end{array}$

$\begin{array}{llll}\begin{array}{l}\text { Number of patients } \\ \quad \text { Males }\end{array} & 14 & & \\ \quad \text { Females } & 9 & & \\ \text { Age mean (SD) } & 14.4(10.4) & & 17 \\ \text { Number of operations } & 26 & 9 & 17 \\ \quad \text { Unilateral EC-IC anastomosis } & 25 & 8 & 0 \\ \quad \text { Bilateral EC-IC anastomosis } & 1 & 1 & 17 \\ \begin{array}{l}\text { Outcome } \\ \text { No postoperative deficits }\end{array} & 25 & 8 & 0 \\ \quad & & & \end{array}$

Group 1: Cases with operation within 48 hours after $\mathrm{H}_{2}{ }^{15} \mathrm{O}-\mathrm{PET}+$ acetazolamide; Group 2: Cases with operation later than 48 hours after $\mathrm{H}_{2}{ }^{15} \mathrm{O}-\mathrm{PET}$ +acetazolamide; ${ }^{*}$ Patient died 4 days after operation 
Table 2. Values of blood gas analysis in all patients and patient subgroups

All patients

26

665.19

$\pm 770.24$

surgery (hours) $\pm \mathrm{SD}$

Intraoperative values

$\mathrm{pH}_{\text {mean }}$

\pm SD

$\mathrm{HCO}_{3}-{ }_{\text {mean }}^{-}$(umol/l)

\pm SD

BE

$\mathrm{PaCO}_{2 \text { mean }}(\mathrm{kPa})$

$\pm \mathrm{SD}$

Postoperative values

$\mathrm{pH}_{\text {mean }}$
$\pm \mathrm{SD}$
$\mathrm{HCO}_{3}^{--}$mean (umol/l)
$\pm \mathrm{SD}^{-}$

BE

$\begin{array}{ll} & --4.3 \\ & \pm 3.0 \\ & \\ \mathrm{PaCO}_{2 \text { mean }}(\mathrm{kPa}) & 4.5 \\ \pm \mathrm{SD} & \pm 1.0\end{array}$

7.370

$+0.059$

19.2

$\pm 2.4$

-- 4.7

$\pm 3.2$

4.5

$\pm 0.5$

7.383

$\pm 0.077$

19.6

$\pm 2.5$
Group 1

Group 2

9

17

23.37

$\pm 12.21$

1005.03

$\pm 686.10$
7.328

$\pm 0.057$ $p<0.0001$

7.393

$+0.047$

17.6

$\pm 2.2$

$p=0.0165$

-- 7.0

$\pm 3.3$

$p=0.0165$

20.1

$\pm 2.1$

$--3.5$

$\pm 2.4$

4.5

4.5

$\pm 0.5$

$\pm 0.5$

ns

7.362

$\pm 0.092$

7.395

$+0.068$

ns

18.1

$\pm 2.3$

-- 5.7

$\pm 3.6$

-- 3.5

ns

20.5

$\pm 2.2$

$p=0.0132$

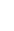


statistical significant; $\mathrm{ns}=$ statistical not significant; Statistical significance was assumed at a p-value $<0.05$.

Figure 1:

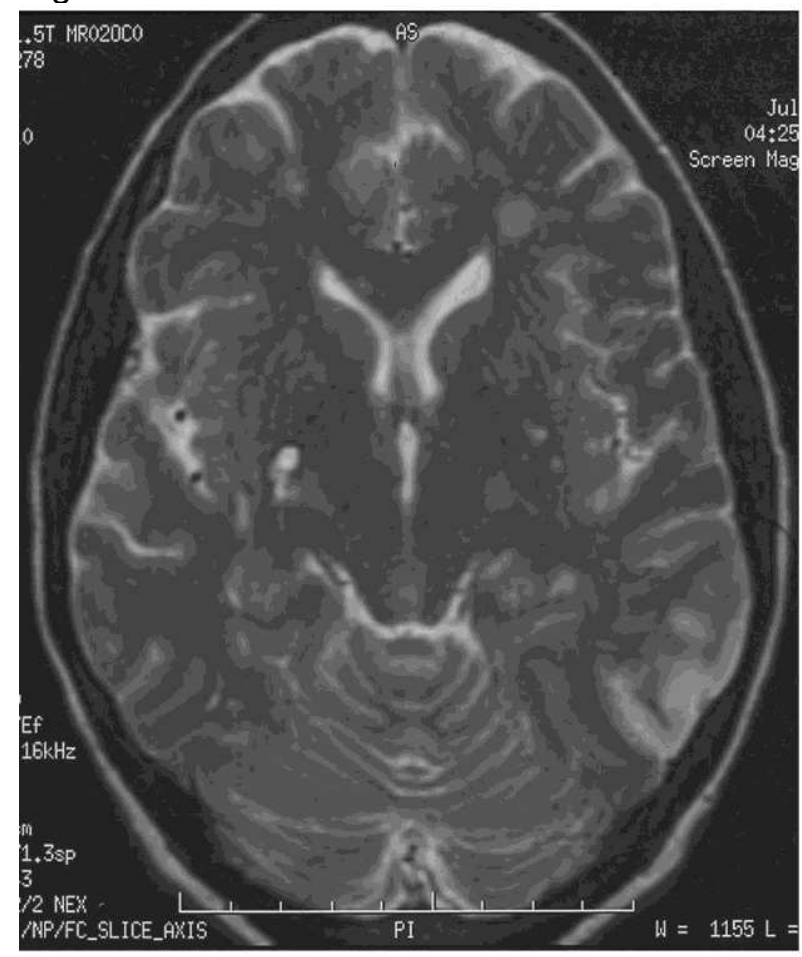

Figure 2:
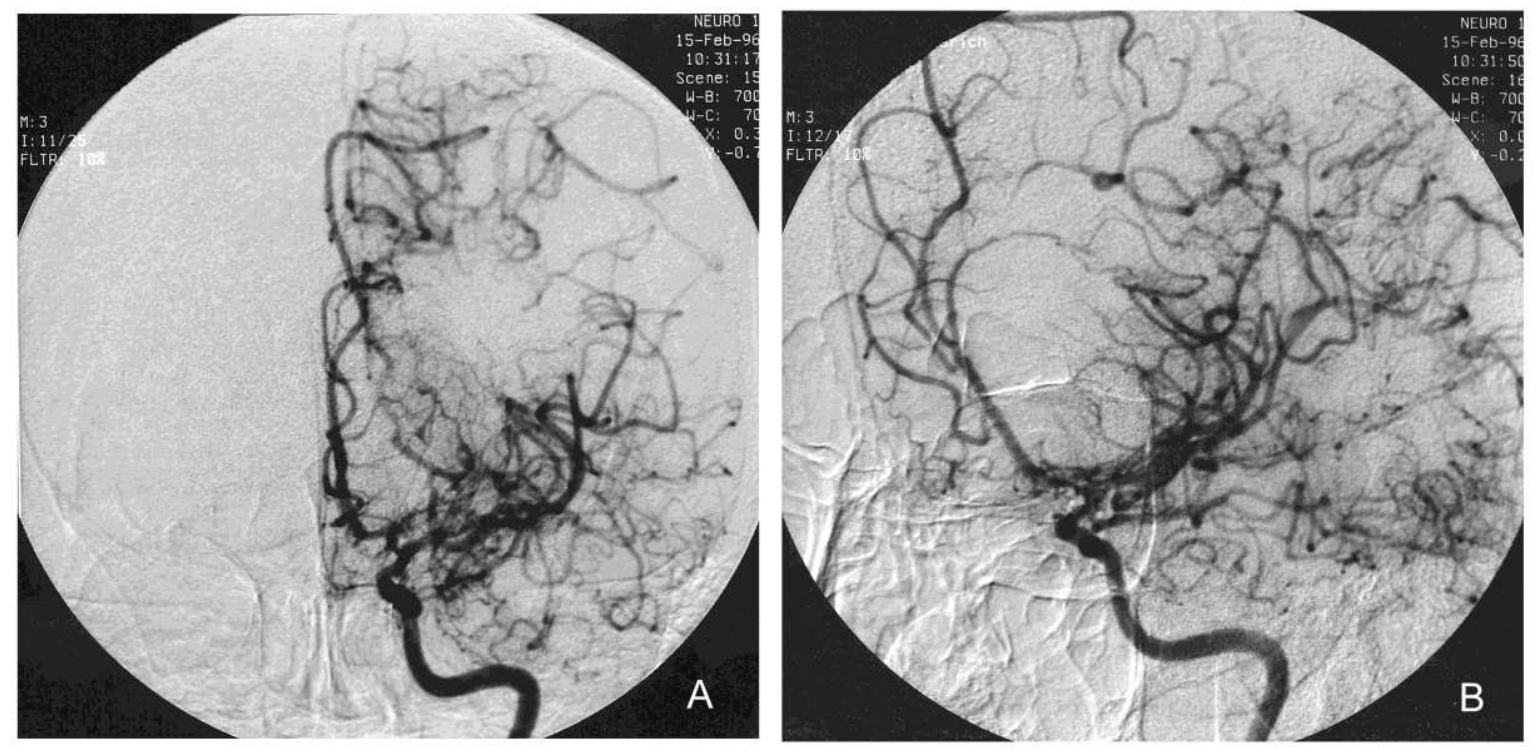

Figure 3: 

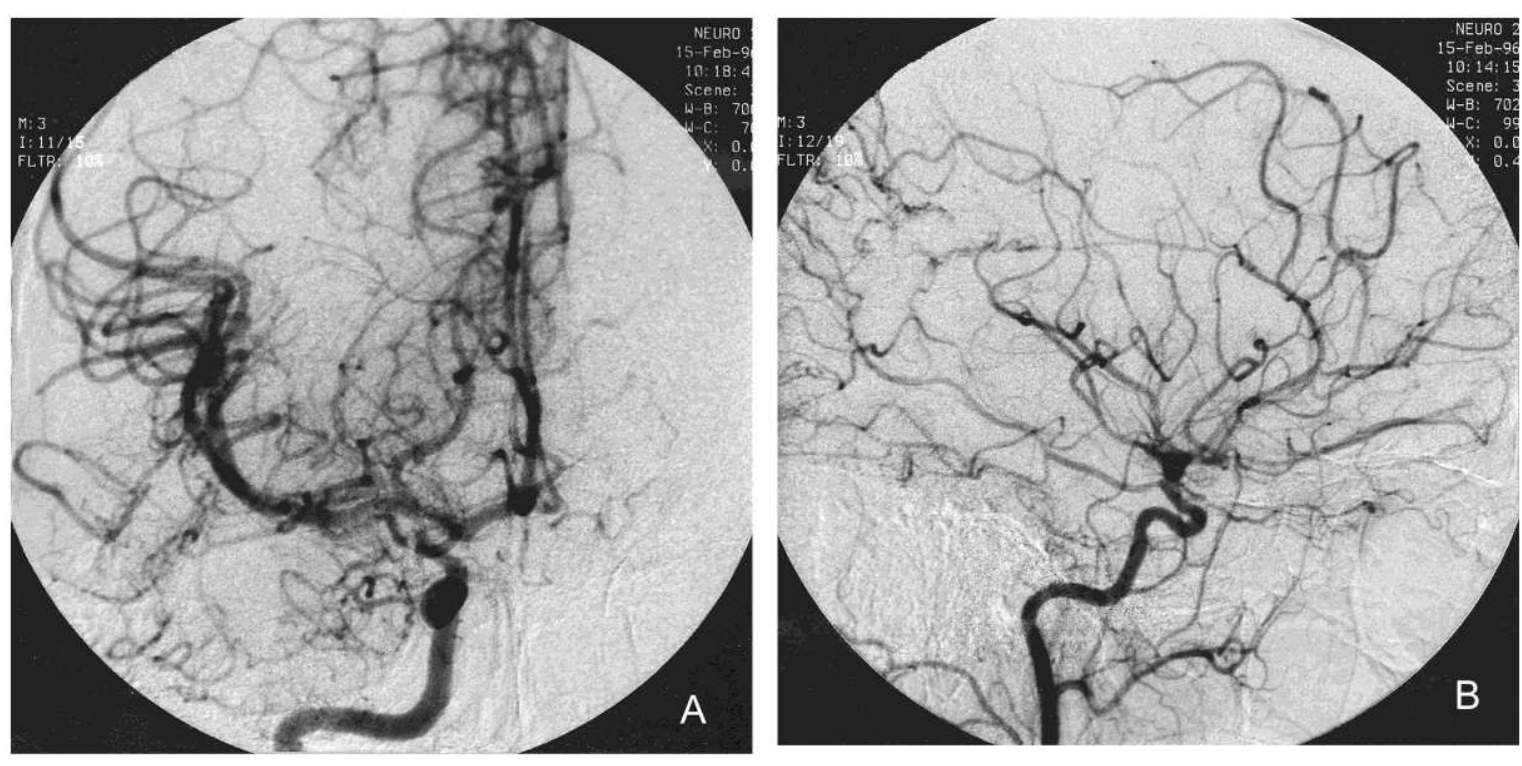

Figure 4:

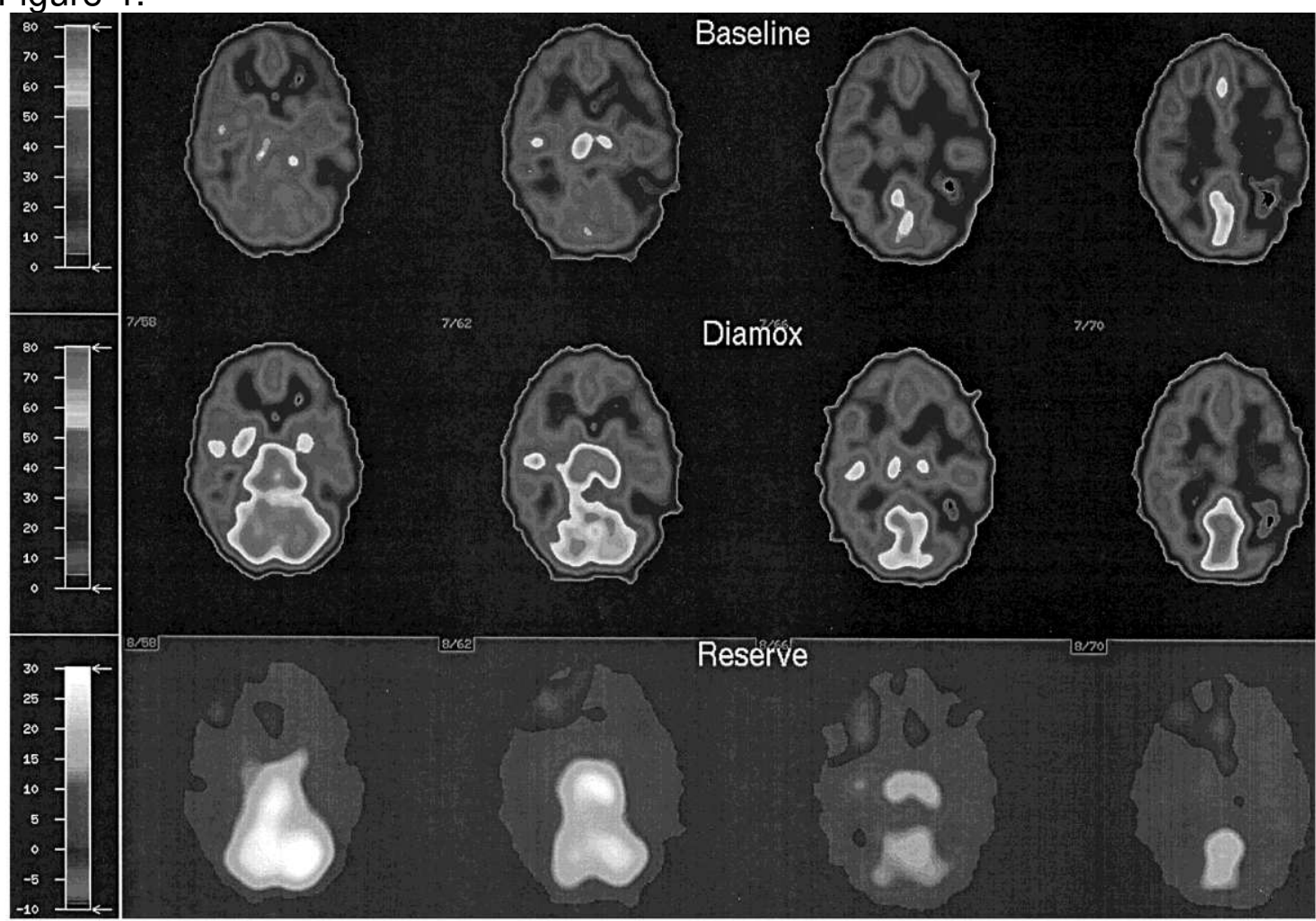

Figure 5: 

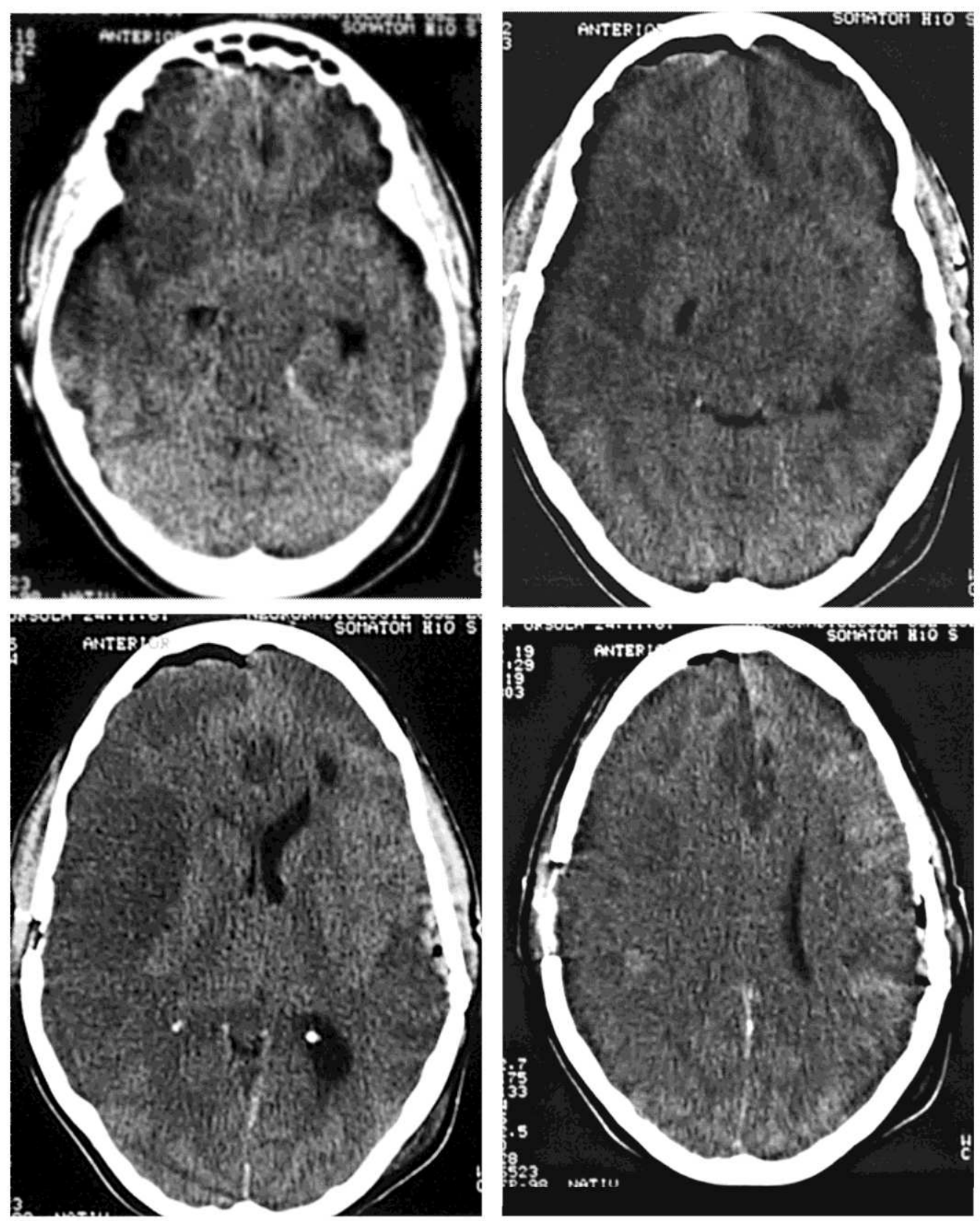